\title{
Halogenated flame retardants in the sediments of the Chinese Yellow Sea and East China Sea
}

\author{
Yanan Li ${ }^{\text {a, c }}$, Xiaomei Zhen ${ }^{\text {a, b, c }}$, Lin Liu ${ }^{\text {a, b, c }}$, Chongguo Tian ${ }^{\text {a }}$, Xiaohui Pan ${ }^{\text {a }}$, \\ Jianhui Tang ${ }^{\mathrm{a}, *}$ \\ ${ }^{a}$ Key Laboratory of Coastal Environmental Processes and Ecological Remediation, Yantai Institute of Coastal Zone Research, Chinese Academy of Sciences, \\ Yantai, 264003, China \\ b State Key Laboratory of Organic Geochemistry, Guangzhou Institute of Geochemistry, Chinese Academy of Sciences, Guangzhou, 510640, China \\ ${ }^{\mathrm{c}}$ University of Chinese Academy of Sciences, Beijing, 100049, China
}

\section{H I G H L I G H T S}

- Halogenated flame retardants were investigated in the sediments of Yellow and East China Seas.

- DBDPE was the predominant contaminant and is one order of magnitude higher than BDE 209.

- High levels of HFRs were found in the depositional zones of the Yellow Sea.

- HFRs from the Bohai Sea was the major source of HFRs in the Yellow Sea.

- Yangtze River contributed less HFRs to the sediments of East China Sea.

\section{A R T I C L E I N F O}

\section{Article history:}

Received 7 April 2019

Received in revised form 12 June 2019

Accepted 14 June 2019

Available online 15 June 2019

Handling Editor: Myrto Petreas

\section{Keywords:}

DBDPE

Yellow Sea

Long-range transport

Sediment

Deposition zone

Brominated flame retardants

\section{G R A P H I C A L A B S T R A C T}

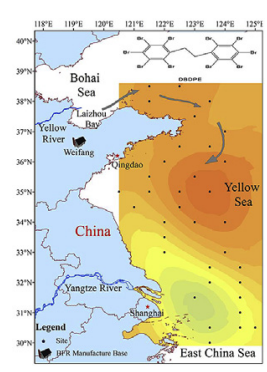

\begin{abstract}
A B S T R A C T
With the phasing out of traditional polybrominated diphenyl ethers (PBDEs), significant volumes of alternative brominated flame retardants (aBFRs) are being used and released into the environment compartment, especially in coastal regions. The levels and distribution of PBDEs, aBFRs, and dechlorane plus (DPs) were investigated in the surface sediments of the Yellow Sea (YS) and East China Sea (ECS) to examine the distribution and sources of these hydrophobic contaminants. The level and distribution of pollutants in the sediments of YS and ECS show obvious regional differences. As a major replacement for decabromodiphenyl ether (BDE 209), decabromodiphenyl ethane (DBDPE) was the dominant compound observed in the surface sediments, with a concentration one order of magnitude higher than that of BDE 209. High concentrations were found in the depositional zones of the YS, indicating that these contaminants may originate from land-based pollution sources (likely from the Laizhou Bay manufacturing base) near the Bohai Sea. The pollutants can be carried by the coastal current together with the sediment from the Yellow River, transported through the Bohai Strait and deposited in the mud zone of Northern and Southern YS. Low levels of halogenated flame retardants (HFRs) were found in the estuary of the Yangtze River and ECS, indicating that Yangtze River contributes less HFRs to the region. Riverine discharge, atmospheric deposition, surface runoff, ocean current system, and mud area deposition effects may be significant factors influencing the distributions of HFRs.
\end{abstract}

() 2019 Elsevier Ltd. All rights reserved.

\footnotetext{
* Corresponding author.

E-mail address: jhtang@yic.ac.cn (J. Tang).
} 


\section{Introduction}

Halogenated flame retardants (HFRs) are synthetic organic compounds that are commonly added to polymer materials to prevent ignition or inhibit flame propagation. These compounds are widely used in plastics, clothing, furniture, textiles, and electronics. Both brominated flame retardant (BFRs) and chlorinated flame retardant (CFRs) are classes of HFRs. Recently, China has become one of the largest consumers of flame retardants with an annual growth rate of HFR consumption as high as 7\%, of which BFRs accounted for a large proportion (Fink et al., 2008). In 2013, HFRs comprised $31 \%$ of the global market for flame retardants (Flame retardants-online, 2014).

Among BFRs, polybrominated diphenyl ethers (PBDEs) have been widely used as flame retardants in commercial and industrial products since 1960s (Li et al., 2012). In 2009, commercial penta- and octaBDEs were officially classified as persistent organic pollutants (POPs) and listed in Annex A of the Stockholm Convention (Stockholm Convention Secretariat, 2009). Lately, deca-BDE was also listed as POPs of the Stockholm Convention in 2017. Due to the properties of persistence, bioaccumulation, and toxicity to organisms, PBDEs (penta-, octa-, and deca-BDE) have been restricted and are being replaced globally (www.pops.int). The production and utility of penta- and octa-BDE were ceased with the European Union (EU) ban in the early 2000s (Wu et al., 2017). To cope with these international regulations regarding the production and usage of PBDEs and achieve strict fire control standards, alternative brominated flame retardants (aBFRs) have been gradually replacing PBDEs, and some other nonPBDE flame retardants have been produced by manufacturers. Examples of these alternatives include pentabromotoluene (PBT), 2,3-diphenylpropyl-2,4,6-tribromophenyl ether (TBP-DPTE), pentabromoethylbenzene (PBEB), hexabromobenzene (HBB), 2-ethylhexyl-2,3,4,5-tetrabromobenzonate (EH-TBB), 1,2-bis(2,4,6tribromophenoxy)ethane (BTBPE), 1,2-Bis(pentabromophenyl) ethane (DBDPE), and dechlorane plus (DPs) (Bergman et al., 2012). The annual production volume of DBDPE is estimated to be as high as 12,000 tons in the Chinese market (Chen et al., 2013). Recently, some studies have also reported that the DBDPE levels were higher than those of BDE 209 in many environmental media (Chen et al., 2013; Zheng et al., 2015)). aBFRs have been produced for many decades and their production volume is increasing rapidly due to the recent phasing out of PBDEs. Thus, with the gradual trend of prohibition and replacement of traditional PBDEs, a wide variety of aBFRs have been quickly developed, especially for DBDPE. Recent reports also have indicated that these aBFRs are becoming widespread in the environment (de Wit and Muir, 2010). DPs are the most common CFRs and have been widely used in electronics, including circuit boards, cables, wire coatings, and other polymeric materials (Sverko et al., 2011; Xiang et al., 2014). DPs are bioavailable, bioaccumulative, exhibit potential physiological toxicity to organisms (Yu et al., 2010), and largely exists as two isomers: syn-DP and anti-DP.

Most HFRs have been widely detected in the atmosphere (Cetin and Odabasi, 2008) (Melymuk et al., 2012), seawater (Moeller et al., 2011), sediments (Chen et al., 2013), and other environmental media, as well as in humans (Mitchell et al., 2012; Zhao et al., 2008). Because of their high octanol-water partition coefficient (Kow) and hydrophobicity, HFRs are readily adsorbed on particles and become enriched in sediments in coastal regions (Zhen et al., 2018). Marine sediments are considered as major environmental sinks of HFRs. Considering the persistence and toxicity of HFRs, their accumulation in sediments could pose serious ecological threats to marine organisms. Therefore, it is urgent to search for the distribution and origin of HFRs in the marine environment so that their potential impact on ecosystem can be illuminated.

The Yellow Sea (YS) and East China Sea (ECS) are two important
Western Pacific marginal seas in China, located between the Chinese mainland and Korean Peninsula. The average depth of the YS is $44 \mathrm{~m}$ and the ECS's mean depth (350) is deeper than that of the YS. ECS is more open to the west Pacific Ocean and frequently influenced by the seasonal variability of East Asian monsoons (Ren et al., 2006). With the acceleration of industrialization and urbanization, increasing amount of discharge of land-based wastes and pollutants have resulted in deteriorating marine environment quality in the YS and ECS. Their adjacent sea receives a large amount of riverine discharges and atmospheric particles carrying pollutants. The total amount of industrial wastewater transported from coastal cities to the YS has reached 305,520,000 tons (SOA, 2014). The Chinese shelf seas (YS and ECS) are distinctly influenced by large river (the Yellow and Yangtze River) delivering a large amount of terrestrial sediment to the coastal ocean (Wang et al., 2011). The total particulate matters imported from the Yellow River and Yangtze River into the YS and ECS accounts for $10 \%$ of the total amount of particulates imported into the oceans by rivers all over the world each year, which causes particulates carrying organic pollutants to be entered into the oceans (Milliman and Meade, 1983). Additionally, a large number of BFRs attached to particles are transmitted from the Bohai Sea ( BS ) ultimately entering into the YS (Wang et al., 2017) by hydrodynamic condition and sediment alongshelf transportation. The YS connect with BS and exchange seawater through the Bohai Strait. The BS coastal current and circulation system composed of the YS warm current and the YS coastal current play an important role in the migration and deposition of sediments transported from rivers to the YS. Many large factories exist along the Yellow and Yangtze Rivers, which transport large amount of river particulates via long-range sediment dispersal processes to the YS and ECS, respectively (Hu et al., 2013; Lim et al., 2007). Organic contaminants in marine environments largely originate from the terrestrial emissions, such as riverine inputs, urban surface runoff, and atmospheric deposition (Wang et al., 2016).

The objectives of this study were: (1) to explore the occurrence and spatial distribution of HFRs in the surface sediments of the YS and ECS and (2) to assess the probable sources of HFRs in the sediments. Previous studies regarding HFRs in the seas of China focused mainly on PBDEs in sediments, and no data regarding levels of aBFRs are available for this area.

\section{Material and methods}

\subsection{Sample collection}

Fig. 1 shows the sampling stations and the background of the study region. In October 2017, during a research cruise campaign (R/V: Beidou), 38 surface sediment samples (top $5 \mathrm{~cm}$ ) were collected from the YS and ECS using a stainless steel box corer. All collected samples were instantly stored at $-20^{\circ} \mathrm{C}$ before freezedrying.

\subsection{Extraction and analysis}

The sediment samples were freeze-dried, pulverized, homogenized, wrapped with filter paper, and Soxhlet extracted by dichloromethane (DCM) for $24 \mathrm{~h}$. Prior to extraction, PCB 209 and ${ }^{13} \mathrm{C}$-HBB were added as surrogate standards. The extracts were concentrated to approximately $3-4 \mathrm{~mL}$ using rotary evaporator. Next, the concentrated extracts were purified using a silica gel column (including $1 \mathrm{~g}$ sodium sulfate and $2.5 \mathrm{~g}$ silica gel $10 \%$ deactivated). The eluting solution consisted of $20 \mathrm{~mL}$ of hexane and the final extracts were concentrated to approximately $1 \mathrm{~mL}$ in hexane. The internal standard (BDE 77) was added to every sample 


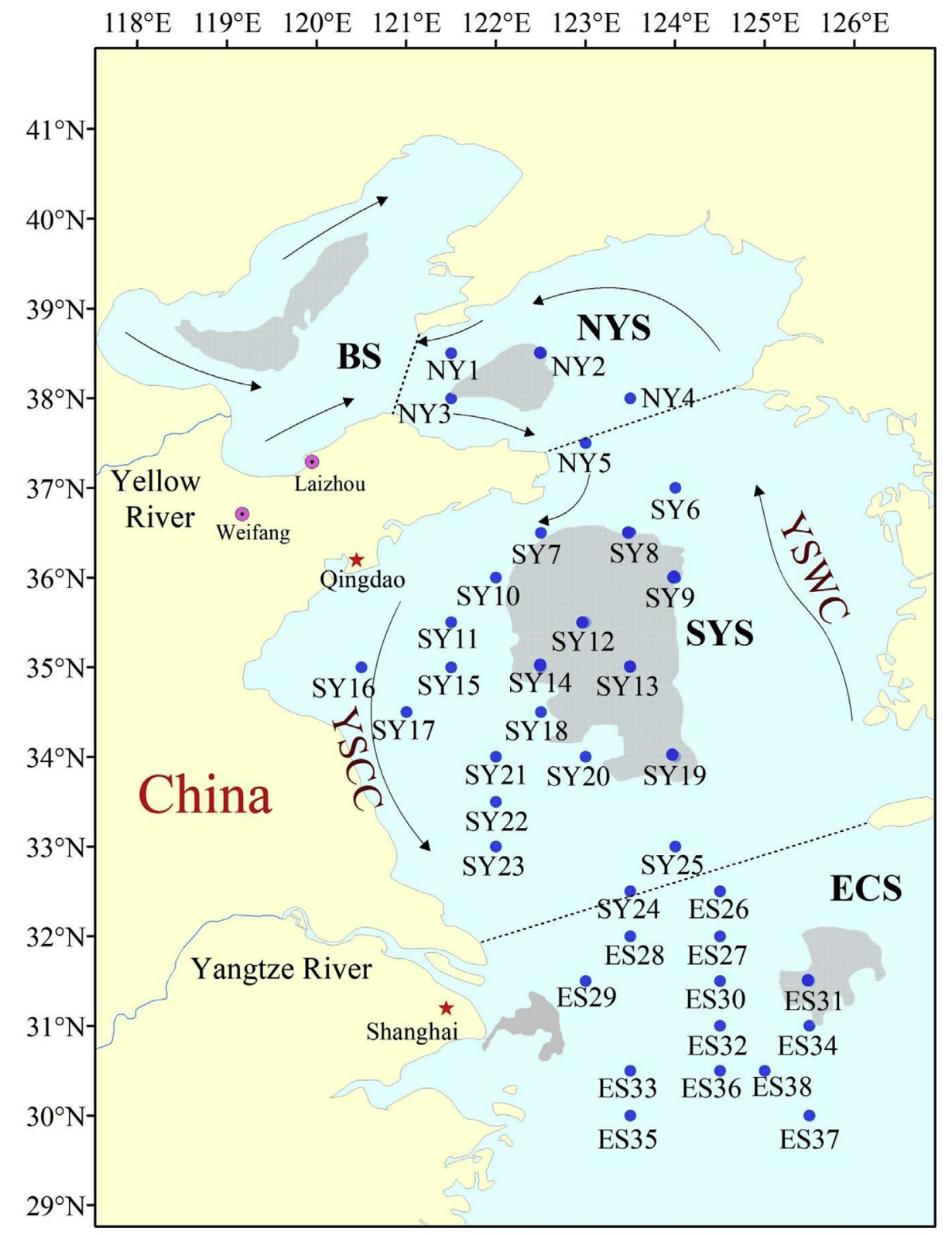

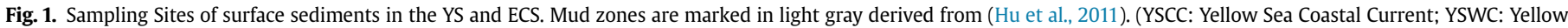
Sea Warm Current). (For interpretation of the references to colour in this figure legend, the reader is referred to the Web version of this article.)

before instrumental analysis. PBDE standards mixture (BDE 28, 47, $99,100,153,154,183$, and 209) and seven aBFRs (PBT, PBEB, HBB, TBP-DPTE, EH-TBB, BTBPE, and DBDPE) were obtained from Wellington Laboratories (Canada).

An Agilent 7890A gas chromatograph (GC) coupled with a 5975C mass selective detector (MSD) was used to identify and quantify the PBDEs, aBFRs, and DPs working with chemical ionization $(\mathrm{CI})$. The negative chemical ionization $(\mathrm{NCI})$ mode was applied. A DB-5HT $(15 \mathrm{~m} \times 0.25 \mathrm{~mm}$ ID, $0.1 \mu \mathrm{m}$ film thickness $)$ capillary column was used and the GC temperature program was set as follows: initially $80^{\circ} \mathrm{C}$ for $2 \mathrm{~min}$, increased to $200^{\circ} \mathrm{C}$ at $10^{\circ} \mathrm{C}$

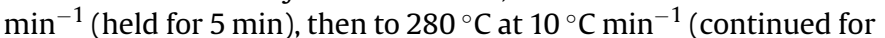
$5 \mathrm{~min}$ ), and finally to $310^{\circ} \mathrm{C}$ at $5^{\circ} \mathrm{C} \mathrm{min}^{-1}$ (continued for $5 \mathrm{~min}$ ). The injection temperature was $280^{\circ} \mathrm{C}$ and the posting run temperature was $320^{\circ} \mathrm{C}$ for $5 \mathrm{~min}$. The sample injection volume was $1 \mu \mathrm{L}$ and splitless injection mode was used.

\subsection{Quality control and quality assurance}

Every 12 samples, a procedural blank in which solvent with filter paper used to wrap the sediments and a duplicate sample were processed for quality control and assurance. In this study, the method detection limit (MDL) was derived from the procedural blanks and considered to be the mean concentration of the field blanks plus three times standard deviations of the blanks. The MDL ranges in the sediments were $0.46-19.8 \mathrm{pg} \mathrm{g}^{-1}$ for PBDEs, $0.73-3.41 \mathrm{pg} \mathrm{g}^{-1}$ for DPs, and $2.37-393 \mathrm{pg} \mathrm{g}^{-1}$ for aBFRs. The mean recoveries of $\mathrm{PCB} 209$ and ${ }^{13} \mathrm{C}-\mathrm{HBB}$ were $80.5 \pm 1.0 \%$ and $65.1 \pm 2.1 \%$ as determined from the solvent blanks, respectively. The mean recoveries were $76.1 \pm 7.4 \%$ for PCB 209 and $63.5 \pm 3.2 \%$ for ${ }^{13} \mathrm{C}-\mathrm{HBB}$ in the 38 samples. All concentrations of HFRs were not corrected for recovery. The linearity of the experimental method was determined and checked by calibration curves generated from 
the six concentration gradients of standard solutions. The values below the MDL were defined as not detected (n.d.). In the following sections, $\Sigma_{7}$ PBDEs represents the sum of BDE 28, 47, 99, 100, 153, 154 , and 183 , and $\Sigma_{6}$ aBFRs is the sum of PBT, PBEB, TBP-DPTE, HBB, EH-TBB, and BTBPE.

\subsection{Total organic carbon (TOC) and grain size of sediments}

Carbonates were removed using hydrochloric acid $(\mathrm{HCl})$ before determination of total organic carbon (TOC) and the TOC concentration was measured using an element analyzer (CHNS Vario Ei III, Elementar). The grain size of the surface sediments was determined using a laser particle characterization system (Mastersizer 2000; Malvern Instruments, Malvern, UK).

\section{Results and discussion}

\subsection{Concentration and comparison of HFRs in the sediments}

Table 1 shows the HFRs concentrations in the Northern Yellow Sea (NYS), Southern Yellow Sea (SYS), and East China Sea (ECS). The $\Sigma_{7}$ PBDEs and BDE209 concentrations were $0.3-108.5 \mathrm{pg} \mathrm{g}^{-1} \mathrm{dw}$ and $1.1-924 \mathrm{pg} \mathrm{g}^{-1} \mathrm{dw}$, with mean values of 20.4 and $127 \mathrm{pg} \mathrm{g}^{-1}$ dw, respectively. $\Sigma_{6}$ aBFRs and DBDPE concentrations were ranged from n.d. to $293 \mathrm{pg} \mathrm{g}^{-1} \mathrm{dw}$ (with a mean of $60.2 \mathrm{pg} \mathrm{g}^{-1} \mathrm{dw}$ ) and from n.d. to $9460 \mathrm{pg} \mathrm{g}^{-1} \mathrm{dw}$ (with a mean of $1700 \mathrm{pg} \mathrm{g}^{-1} \mathrm{dw}$ ), respectively. Generally, DBDPE was the predominant compound, followed by BDE 209 and DPs. BDE 209 concentration was one order of magnitude lower than that of DBDPE, but one order of magnitude higher than that of DPs (with a mean of $18.2 \mathrm{pg} \mathrm{g}^{-1} \mathrm{dw}$ ).

The concentration and spatial distribution of HFRs in sediments is shown in Fig. 2. For traditional PBDEs, it is clear that BDE 209 was the predominant congener, similar to the data reported in other studies (Li et al., 2012; Wang et al., 2016). This can be attributed to the relatively high consumption of commercial Deca-BDE in the Chinese market. BDE 209 accounted for $77.2 \pm 17.3 \%$ of all the PBDEs congeners detected in all sediments, followed by BDE 99 (9.2\%), BDE 47 (4.3\%), and BDE 153 (2.9\%). The highest level was found at site S9, followed by sites S2 and S3, which were all located in the mud area of YS. The detection rate of BDE 209 was $100 \%$ and for the other PBDE congeners it followed the order: BDE $99=\mathrm{BDE}$ $28>$ BDE $47>$ BDE $183>$ BDE $154>$ BDE $153>$ BDE 100 . The percentages of PBDE congeners are shown in Fig. 3. The variation reflected the different features and properties of PBDE congeners and also their emission sources. Among the seven PBDE congeners, BDE-47, 99, 153, and 183 were most abundant, in agreement with a previous study on the sediment cores in the southern YS (Wang et al., 2017). High percentages of BDE 47 and BDE 99 implied that the emissions were from extensive usage of commercial penta-BDE. The slightly elevated percentages of BDE 153 and 183 likely resulted from the usage of octa-BDE, with BDE 183 often thought as an indicator of the presence of octa-BDE (La Guardia et al., 2006). In addition, penta- and octa-BDE were the two most commonly used
PBDEs in commercial products over the past few years. As shown in Table S1, Pearson correlations showed that individual PBDE congeners were significantly correlated with each other overall, despite several exceptions, suggesting common sources and fates of the PBDE congeners.

For the aBFRs, six aBFRs were detected in the sampled surface sediments except PBEB (detection rate in order: DBDPE $>$ EHTBB $>$ PBT $>$ BTBPE $>$ TBP-DPTE $>$ HBB). For EH-TBB and PBT, which had over $70 \%$ detection frequencies, their concentrations ranged from n.d. - 221.4 and n.d. - $2.72 \mathrm{pg} \mathrm{g}^{-1} \mathrm{dw}$, respectively. BTBPE, TBPDPTE and HBB were detected in $44.7 \%, 34.2 \%$, and $21.1 \%$ of all samples, respectively, at concentrations of n.d.- 12.01, n.d. - 176.73, and n.d. - $12.06 \mathrm{pg} \mathrm{g}^{-1} \mathrm{dw}$. DBDPE, which is commonly used as a substitute for BDE 209, was detected in all sediment samples except for one site, indicating that this contaminant was prevalent in marine sediments. As phasing out and prohibiting of Deca-BDE, DBDPE has been used more and more frequently and the usage might be increasing. The higher level of BDE 209 in marine sediments was observed at site NY2, NY3 and SY14, which coincided with the distribution of DBDPE. High level region of DBDPE concentrated in deposition area in YS. The highest DBDPE level was found at site NY2, followed by at sites SY14, SY20, NY3, and SY12 (all concentration above $3700 \mathrm{pg} \mathrm{g}^{-1} \mathrm{dw}$ ), which were completely located in the mud zone of the YS. There are two huge mud zones in the Yellow Sea, one in the center of South Yellow Sea and the other in the North Yellow Sea. The major source of these sediments is originated from the Yellow River, across the Bohai Strait and deposited in the Yellow Sea, whereas atmospheric deposition contributes less than 2\% (Qiao et al., 2017). Many large BFRs manufacturers are located near Laizhou Bay and Weifang (Shandong Province) because they are close to bromine-rich seawater sources, affecting the environmental quality of Bohai Sea (BS). It has been reported that the level of PBDEs, especially for BDE 209, in the marine sediments of Laizhou Bay is much higher than that reported in this study (Pan et al., 2011). Furthermore, studies have reported that the atmosphere around Laizhou Bay and Weifang contained significant amounts of BDE 209 and DBDPE, which can be attributed to the point sources of local factories (Zhao et al., 2013; Lin et al., 2013). Zhen et al. (2016) showed that the BFRs in the sediments of the coastal YS (Sisili Bay and Taozi Bay) were greatly affected by land-based emissions via coastal current transport. Coincidently, the contaminant concentration of NY3 was high in this study, as it is adjacent to the two Bays, indicating that these pollutants were transported from BS. Moreover, the level of BFRs in Sisili Bay and Taozi Bay were on the same order of magnitude as that of the YS sites reported in this study. According to the comparison, the concentrations of aBFRs, especially for DBDPE, in this study (41.1-9465 $\mathrm{pg} \mathrm{g}^{-1} \mathrm{dw}$ ) were generally higher than those of previous study (Sishili Bay: $960-6490 \mathrm{pg} \mathrm{g}^{-1} \mathrm{dw}$, Taozi Bay: 530-4150 $\mathrm{pg} \mathrm{g}^{-1} \mathrm{dw}$ ), while PBDEs (including BDE209) showed the opposite trend (this study: $4.5-924.2 \mathrm{pg} \mathrm{g}^{-1} \mathrm{dw}$; Sishili Bay: 250-1180 pg g $^{-1} \mathrm{dw}$, Taozi Bay: n.d. $-620 \mathrm{pg} \mathrm{g}^{-1} \mathrm{dw}$ ). The high proportion of aBFRs accounted for majority of HFRs regardless of

Table 1

Statistics of HFRs (mean and range of value) in the NYS $(n=5)$, SYS $(n=20)$ and ECS $(n=13)$.

\begin{tabular}{|c|c|c|c|c|c|}
\hline \multirow[t]{2}{*}{ Study Area $\left(\mathrm{pg} \mathrm{g}^{-1}\right)$} & \multicolumn{2}{|l|}{ PBDEs } & \multicolumn{2}{|l|}{ aBFRs } & \multirow[t]{2}{*}{ DPs } \\
\hline & BDE 209 & $\Sigma_{7}$ PBDEs & DBDPE & $\Sigma_{6} \mathrm{aBFRs}$ & \\
\hline NYS & $263(9.5-634)$ & $27.8(3.1-108)$ & $3280(102-9460)$ & $68.0(1.9-225)$ & $16.5(1.6-43.6)$ \\
\hline SYS & $158(4.5-924)$ & $25.3(0.3-101)$ & $2068(41.1-6370)$ & 80.7 (n.d.-293) & $25.9(0.1-152)$ \\
\hline ECS & $26.9(1.1-97.5)$ & $9.9(0.4-34.9)$ & 518 (n.d.-1830) & 25.7(n.d.-112) & $6.9(0.8-23.0)$ \\
\hline Total & $127(1.1-924)$ & $20.4(0.3-108)$ & 1700 (n.d.-9460) & 60.2 (n.d.-293) & $18.2(0.1-152)$ \\
\hline
\end{tabular}

$\Sigma_{7}$ PBDEs-the sum of all targeted PBDE congeners except for BDE 209.

$\Sigma_{6}$ aBFRs - the sum of all targeted aBFR congeners except for DBDPE. 

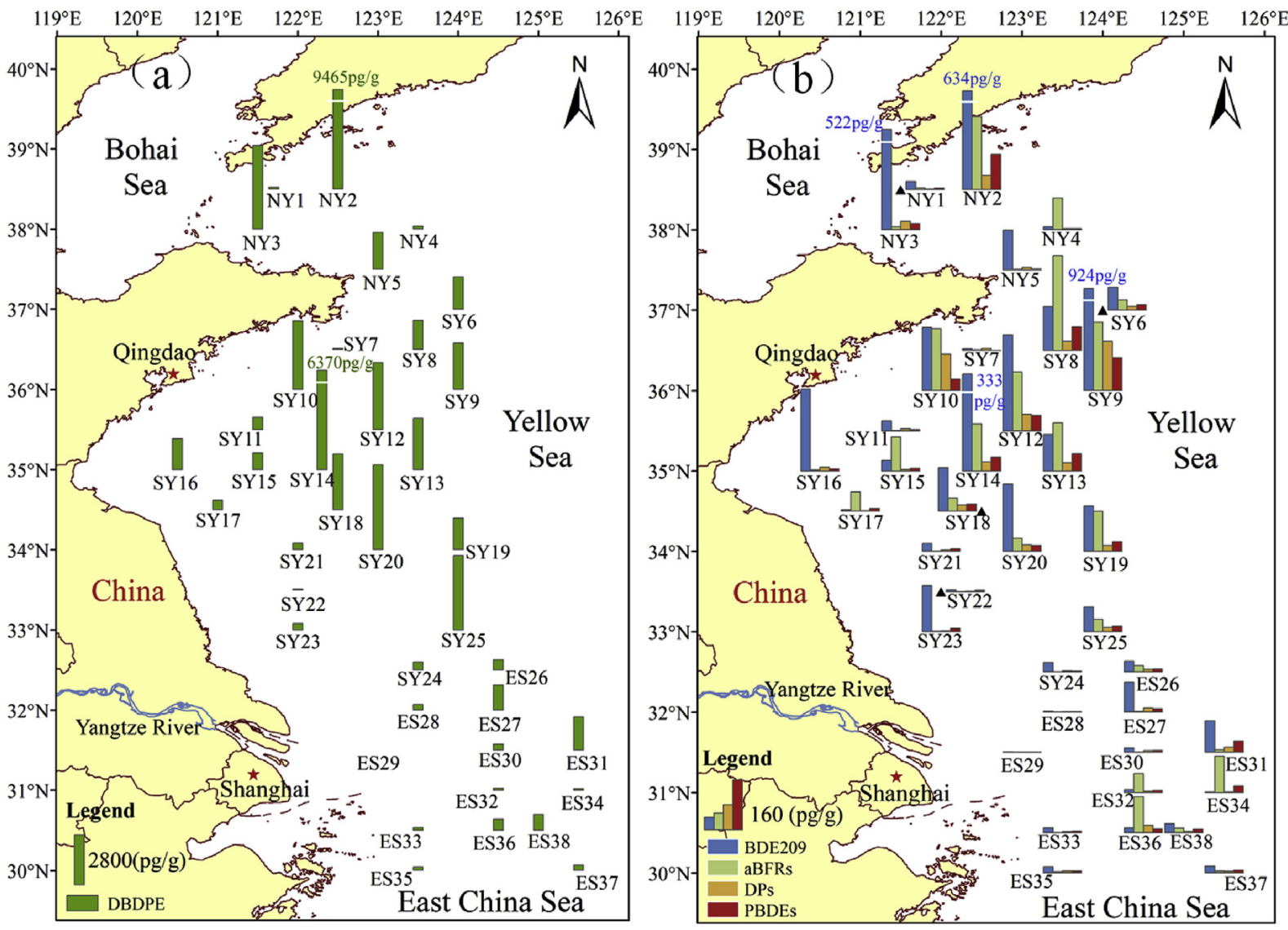

Fig. 2. The concentration and spatial distribution of DBDPE (a) and BDE209, PBDEs (except BDE 209), aBFRs (except DBDPE) and DPs (b) in sediments of the YS and ECS.

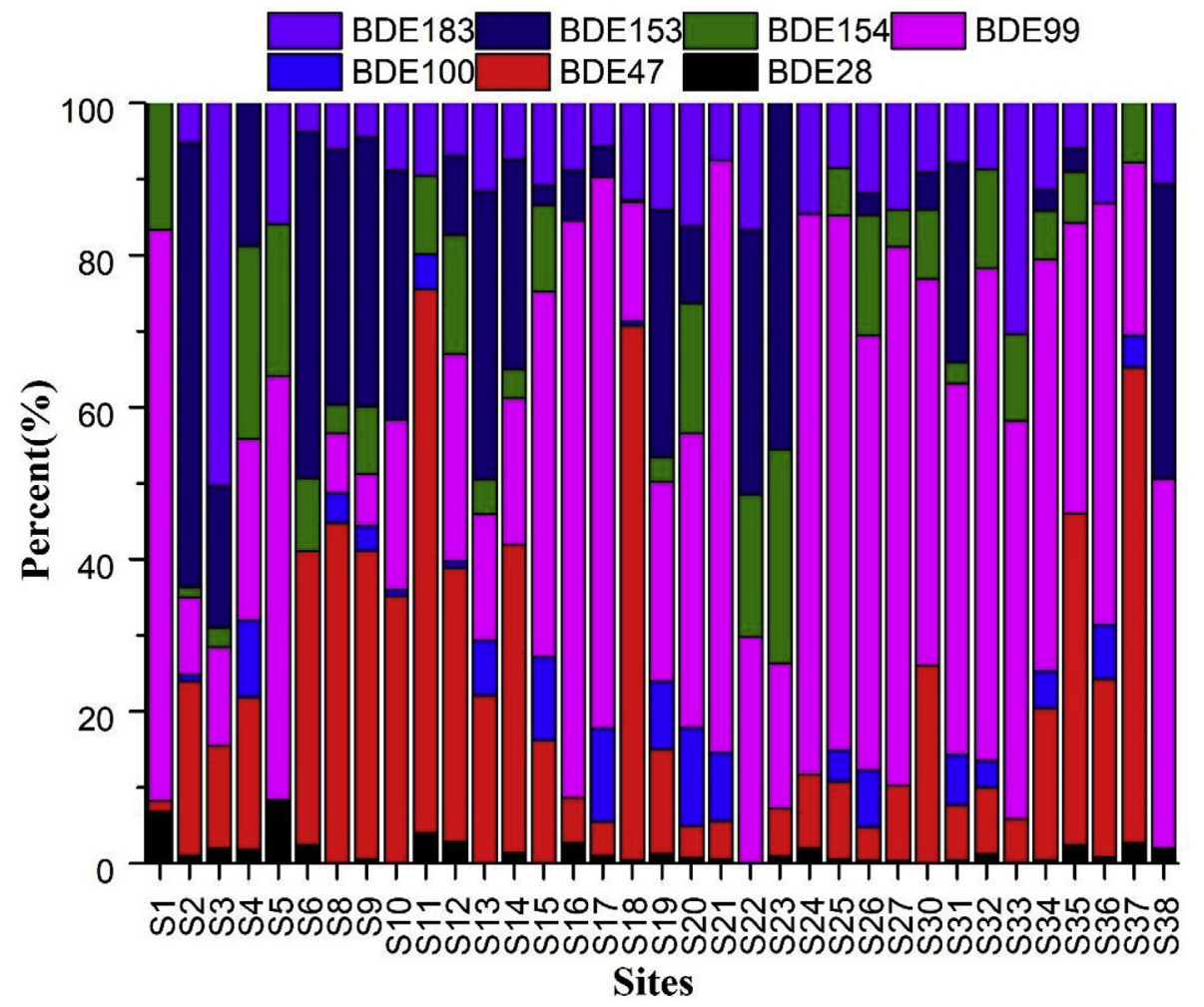

Fig. 3. Compositions of PBDEs (except BDE209) in sediments of the YS and ECS. 
site in the YS or ECS. In general, the compositions of HFRs were dominated by DBDPE and BDE 209 in the sediments, which combinely contributed $90.0 \%$ of the total HFRs. DBDPE/BDE 209 ratio is often used to evaluate a shift in the usage pattern of these two BFRs. The ratio of DBDPE/BDE 209 was calculated in the sediments where both BDE 209 and its substitute DBDEPE were detected in the same sample (except for site ES29 where DBDPE was not detected). In addition, the ratios of DBDPE/BDE209 were greater than 2 (ranged from 2.45 to 113.74 ) in $97 \%$ of the samples, indicating the predominance of DBDPE and the usage of novel DBDPE has exceeded that of the deca-BDE mixture. This suggests that the trend of consuming PBDEs exhibited a slight decline, whereas the usage of aBFRs, especially DBDPE, showed an increasing trend. It should be noted that concentrations of DBDPE in most sediments were higher than the levels of BDE 209, and this phenomenon was also observed in other studies of marine sediments and soils in China (Zheng et al., 2015; Zhen et al., 2016). Compared with BDE 209 and DBDPE, relatively low concentrations of $\Sigma_{7}$ PBDEs (mean of $20.4 \mathrm{pg} \mathrm{g}^{-1} \mathrm{dw}$ ), $\Sigma_{6}$ aBFRs (mean of $60.2 \mathrm{pg} \mathrm{g}^{-1} \mathrm{dw}$ ), and DPs (mean of $18.2 \mathrm{pg} \mathrm{g}^{-1} \mathrm{dw}$ ) were observed in this study. Both anti-DP and syn-DP were detected in all samples except those obtained from SY22 where anti-DP was below the detection limit, highlighting the currently broad distribution of DPs in the marine environment. The concentrations of anti- and syn-DP were n.d. - $132 \mathrm{pg} \mathrm{g}^{-1}$ and $0.06-24.5 \mathrm{pg} \mathrm{g}^{-1}$, respectively. It was apparent that the level of anti-DP was generally higher than syn-DP, which in accordance with the study of coastal sediments in the YS (Zhao et al., 2011). The ratio of the syn-DP to the sum of the two DP concentrations $\left(f_{\text {syn }}\right)$ in the sediment samples was calculated. The mean value $f_{\text {syn }}$ for NYS, SYS, and ECS were $0.22 \pm 0.08,0.31 \pm 0.19$, and $0.31 \pm 0.12$, respectively. Previous studies have shown $\mathrm{f}_{\text {syn }}$ values ranging from 0.2 to 0.35 for commercial DP compounds manufactured and widely applied in North America (Wang et al., 2010). In this study the mean value of $f_{\text {syn }}$ was $0.30 \pm 0.16$ and only 6 of 38 samples showed values higher than 0.35 . The mean $\mathrm{f}_{\text {syn }}$ value in this study was consistent with those in the commercial products. The result indicated that sediments of the YS and ECS may not have stereoselective enrichment of syn-DP.

Table S2 compares the levels of BFRs determined in this study with values obtained in other studies. The PBDE concentrations reported in this study were comparable to those in sediments from four bays in Northern China (Zhen et al., 2016), Yangtze River Delta, East China (Zhu et al., 2013), and Western Arctic Ocean (Cai et al., 2012). This study reported values much lower than the Xiaoqing River in China (Zhen et al., 2018), three bays in South America (Baron et al., 2013), and Llobregat river, Spain (Baron et al., 2014). For aBFRs, the levels in this study were higher than those found in Yangtze River Delta, East China (Zhu et al., 2013), three bays in South America (Baron et al., 2013), and Western Arctic Ocean (Cai et al., 2012), but lower than those in four bays in North China (Zhen et al., 2016), Llobregat river, Spain (Baron et al., 2014), and Xiaoqing River, China (Zhen et al., 2018). These results indicated a relatively moderate level of contamination at the sites studied herein.

\subsection{Spatial distribution and possible source of HFRs}

The concentration and distribution of HFRs in the sediments of YS and ECS show obvious regional differences. Generally, the concentrations of HFRs in the YS were higher than those in the ECS and relatively lower concentrations of HFRs were found in the Yangtze River estuary. As shown in Table 1, the $\Sigma_{17}$ HFRs ranged from 49.1 to $10,500 \mathrm{pg} \mathrm{g}^{-1} \mathrm{dw}$ (mean of $2620 \mathrm{pg} \mathrm{g}^{-1} \mathrm{dw}$ ) in the YS, whereas in the ECS, the $\Sigma_{17}$ HFRs ranged from 2.3 to $1990 \mathrm{pg} \mathrm{g}^{-1} \mathrm{dw}$ (mean of $587 \mathrm{pg} \mathrm{g}^{-1} \mathrm{dw}$ ). The highest level of HFRs was located in site NY2, while the lowest level was located in site ES29.

Higher concentration of the HFRs in the YS mud area might result from the larger number of pollution sources in the Laizhou Bay and it is possible to speculate that these contaminants are likely to be transported from BS through the Bohai Strait and ultimately deposited in the NYS and the Central South Yellow Sea by BS coastal current and YS coastal current (Qiao et al., 2017). The analysis and interpretation are as follows:

The largest manufacturing base of BFRs in Asia is located in Weifang in Shandong province, China and high levels of PBDEs, especially BDE 209, were found in the surface sediments of Laizhou Bay (Pan et al., 2010). In addition, the high abundance of BFRs in atmosphere located near Laizhou Bay mainly resulted from manufacturing and production of BFRs in this region (Lin et al., 2013). The impacts and influences from source region (manufacturing scale and process) were noticeable. This is considered proof that the possible pollutant sources originated from Laizhou Bay (manufacturing activities) for the HFRs in YS and ECS. In addition, the concentration of BFRs in Sisili Bay and Taozi Bay were on the same order of magnitude as that of the NYS reported in this study (Zhen et al., 2016). And Zhen et al. (2016) revealed that HFRs of the two bays were influenced by BFRs manufacturers through current transportation. The majority of finegrained sediments in YS originated from Yellow River directly or indirectly within long range sediment diffusion processes (Hu et al., 2011; Qiao et al., 2017). The sedimentary area in the YS was far away from the direct river source. It was reported that almost $30 \%$ of the Yellow River-derived sediments have been suspension and transferred from BS extending into the YS, travelling far from river mouth (Yang and Liu, 2007). These sediments can reach in the central South Yellow Sea of $-80 \mathrm{~m}$ water depth along with ocean current system (Yang and Liu, 2007). In large ocean current systems, sediments are reported to can transport a long distance from river mouth and form a sediment deposition zone away from the source, within a large-scale alongshore sediment migration (Yang and Liu, 2007). Contaminants (such as HFRs) with high particle affinity in production area (Laizhou Bay) can be transferred to the depositional area attached to fine grained sediments through currents and long-range sediment dispersal processes. As a result, higher concentration of HFRs accumulated with sediments and then deposited in YS mud zone.

Many researchers have found that cyclonic circulations associated with upwelling currents in the YS cold water masses control the sedimentary environment of the mud area in the YS (Shi et al., 2002). The sedimentary environment of mud zone is uniform and stable, which controlled by YS cold water mass, warm current and coastal current. The shelf mud depositional effect (Hu et al., 2011) (fluid transportation of the sediments and sedimentation mechanism) was the main factor influencing the distribution pattern of the contaminants in the YS. With the effect of East Asian monsoon, aerosols could carry organic pollutants from the East Asian continent to the YS and the ECS through atmospheric transportation (Zhang and Gao, 2007). Atmospheric deposition may also be one of the sources of pollutants in the YS and the ECS. There is an obvious high concentration value of BDE 209, $\Sigma_{7}$ PBDEs, DBDPE, $\Sigma_{6}$ aBFRs and DPs in the mud area. Hydrodynamic conditions, riverine substance inputting and mud zone deposition effecting might be the main factors that affected the spatial distributions of HFRs. Details about the HFRs concentrations are listed in Table S3 in the supporting information.

The HFRs concentrations increased from the coastal to central mud areas. Most high concentration readings were observed in the mud area or nearby in both the YS and ECS as shown in Fig. 2. It is clear that DPs predominated in the muddy area. The highest concentration of DPs was located in site SY9, while the lowest 
level was located in site SY22. Site NY2 showed the highest $\Sigma_{17}$ HFRs concentration among all sites, followed by those of SY14, NY3, and SY20, which were all located in the mud area. The sites located in the mud areas showed higher concentrations than their neighboring sites (i.e. the concentration at SY12 was higher than that at SY11; concentrations at SY13 and SY14 were higher than those of SY15 and SY16; concentration of SY18 was higher than that of SY17; concentrations of SY19 and SY20 was higher than that of SY21; and concentration of ES31 was higher than that of ES30). A great deal of the pollutants displayed higher or comparable concentrations in the offshore sediments relative to nearshore sites. Sites located at the nearshore of the YS (SY11, SY17, SY21, and SY22) showed relatively low levels likely because of the YS coastal current (YSCC), which caused dilution by seawater. Lower levels of HFRs were found in the estuary of the Yangtze River and ECS compared with the YS, implying that the Yangtze River contributes less HFRs to this region. It was not surprising that the offshore sites in the mud area demonstrated higher concentrations of contaminants in the ECS. Especially for nearshore sites, the concentrations of HFRs were lower than those of offshore sites, which was likely caused by dilution with Changjiang-derived water.

\subsection{Correlation analysis for the HFRs and physicochemical indicators}

It has been shown that sedimentary parameters (TOC and sediment grain size) can influence the spatial distribution pattern of organic contaminants (Pan et al., 2010; Zheng et al., 2011). The correlations between HFRs and organic carbon in the sediment were studied to investigate whether the organic carbon influenced the transport and fate of HFRs. TOC concentrations in the sediments varied from $0.071 \%$ to $1.034 \%$, with a mean value of $0.413 \%$. It is obvious that high TOC values occur in the central part of the South YS and its distribution is similar to that of HFRs from Fig. 4, which indicates that TOC has a certain influence on the migration and deposition of HFRs. Previous studies have demonstrated that TOC and grain size can significantly affect the distribution of POPs (Zhao et al., 2010; Zheng et al., 2015).

As shown in Fig. S1, the correlations ( $p<0.05$ ) between BDE 209, DBDPE, and TOC were significant in the sediments, indicating that HFR accumulation in the sediment was regulated by organic carbon. Similar results have been reported in the Southern Yellow Sea, China (Wang et al., 2016). As shown in Table S1, the correlation coefficient matrices in the sediment showed that individual PBDE congeners, BFRs, DPs, and TOC were significantly correlated with each other, suggesting similar properties, fates, and sources. Fig. S2 shows the correlations between BDE 209 and DBDPE concentrations in sediments, and these two substances were significantly correlated $(\mathrm{p}<0.01)$. The distribution of DBDPE was similar to that of BDE 209. Due to their structural similarities, these compounds likely displayed similar environmental behaviors and could indicate a common source or origin. However, the correlations observed between median diameter (MD) of the grain and HFRs were poor. The sediment grain size in the YS is relatively small compared with that observed in the ECS, indicating that the depositional environment of the YS involves more fine-grained sediment. Similar to other organic contaminants, it is easily to find that the relative higher HFRs concentration in the central YS demonstrated a consistent relationship with higher TOC contents of sediments (Duan et al., 2013; Hu et al., 2011). HFRs can be easily adsorbed on sediments with smaller grain size and higher TOC due to their high hydrophobicity, which was consistent with the results of other report (Pan et al., 2011).

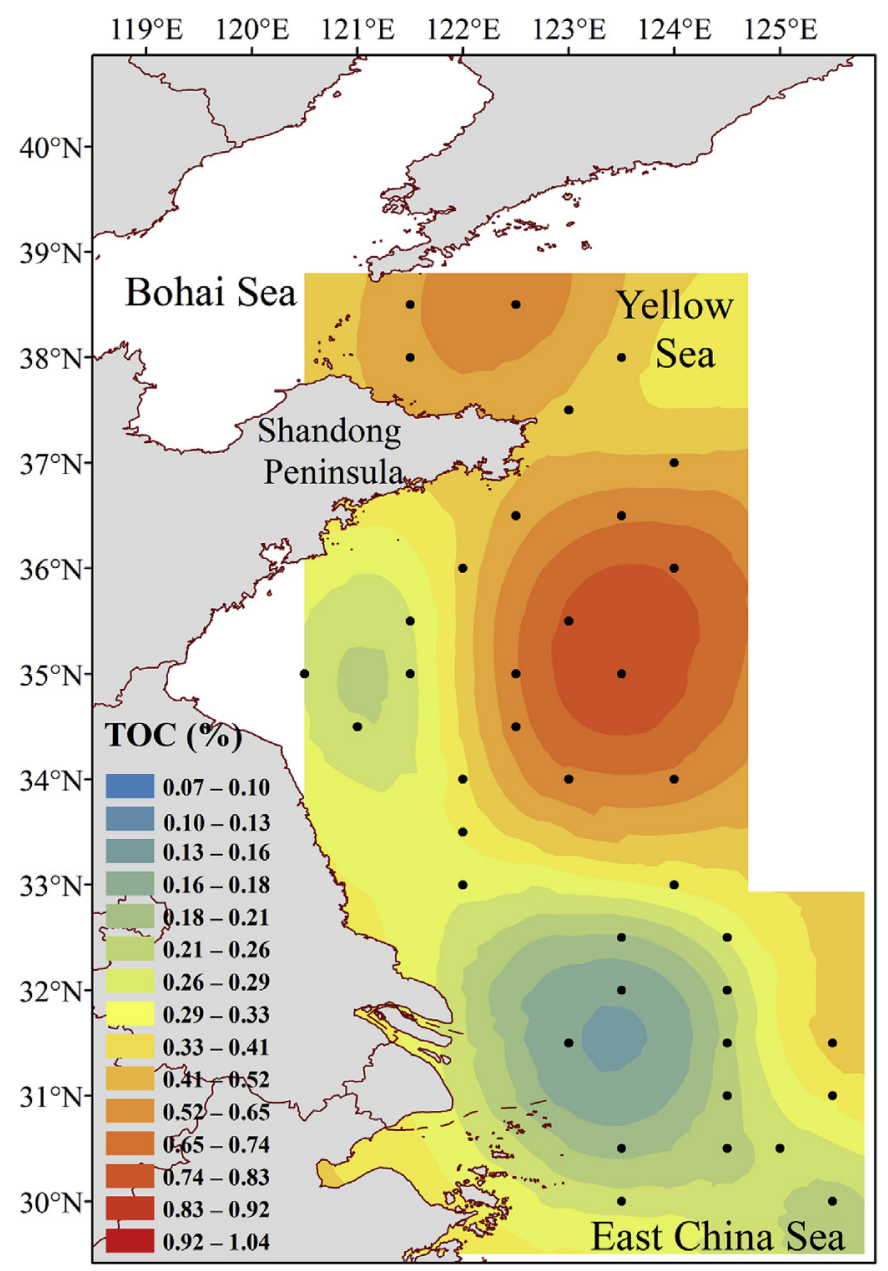

Fig. 4. The concentration and spatial distribution of TOC in sediments of the YS and ECS.

\section{Conclusions}

This study investigated the concentration, composition, and distribution of HFRs in the sediments of the YS and ECS. BDE 209 and DBDPE were the two main HFRs detected in the surface sediments and DBDPE was more abundant than BDE 209. Furthermore, the trend of PBDEs consumption showed a slight decline, while the usage volume of aBFRs, especially for DBDPE, showed an increasing trend. The concentrations and compositional distribution of HFRs in the sediments of YS and ECS show obvious regional differences. HFRs with high particle affinity can be transferred to the depositional area attached to fine-grained sediments through currents and long-range sediment dispersal processes. From inshore to offshore, the HFR concentrations showed a slightly increasing trend due to the presence of mud areas. Owing to riverine substance inputting and ocean current transportation, the higher percentages of HFRs in the YS were potentially derived from land-based emissions of BS. Most high concentrations were observed in the deposition zone or neighboring regions. Moreover, the mud deposition zone on the shelf is likely the major sink of land-originated HFRs in the YS and ECS. With regards to the adverse effects of HFRs on organisms and the general environment, more measurements should be taken to monitor and control HFR pollution. 


\section{Acknowledgement}

This study was supported by the National Natural Science Foundation of China (No. 41773138 and U1806207) and by the seed project of Yantai Institute of Coastal Zone Research, Chinese Academy of Sciences (No. YIC Y855011024). We are grateful for the assistance from the crew of $R / V$ Beidou during the cruise.

\section{Appendix A. Supplementary data}

Supplementary data to this article can be found online at https://doi.org/10.1016/j.chemosphere.2019.06.115.

\section{References}

Baron, E., Gago-Ferrero, P., Gorga, M., Rudolph, I., Mendoza, G., Zapata, A.M., DiazCruz, S., Barra, R., Ocampo-Duque, W., Paez, M., Darbra, R.M., Eljarrat, E. Barcelo, D., 2013. Occurrence of hydrophobic organic pollutants (BFRs and UVfilters) in sediments from South America. Chemosphere 92, 309-316.

Baron, E., Santin, G., Eljarrat, E., Barcelo, D., 2014. Occurrence of classic and emerging halogenated flame retardants in sediment and sludge from Ebro and Llobregat river basins (Spain). J. Hazard Mater. 265, 288-295.

Bergman, A., Ryden, A., Law, R.J., de Boer, J., Covaci, A., Alaee, M., Birnbaum, L., Petreas, M., Rose, M., Sakai, S., Van den Eede, N., van der Veen, I., 2012. A novel abbreviation standard for organobromine, organochlorine and organophosphorus flame retardants and some characteristics of the chemicals. Environ. Int. 49, 57-82.

Cai, M.G., Hong, Q.Q., Wang, Y., Luo, X.J., Chen, S.J., Cai, M.H., Qiu, C.R., Huang, S.Y., Mai, B.X., 2012. Distribution of polybrominated diphenyl ethers and decabromodiphenylethane in surface sediments from the Bering Sea, Chukchi Sea, and Canada Basin. Deep-Sea Res. Part II Top. Stud. Oceanogr. 81-84, 95-101.

Cetin, B., Odabasi, M., 2008. Atmospheric concentrations and phase partitioning of polybrominated diphenyl ethers (PBDEs) in Izmir, Turkey. Chemosphere 71, 1067-1078.

Chen, S.-J., Feng, A.-H., He, M.-J., Chen, M.-Y., Luo, X.-J., Mai, B.-X., 2013. Current levels and composition profiles of PBDEs and alternative flame retardants in surface sediments from the Pearl River Delta, southern China: comparison with historical data. Sci. Total Environ. 444, 205-211.

de Wit, C.A., Muir, D., 2010. Levels and trends of new contaminants, temporal trends of legacy contaminants and effects of contaminants in the Arctic: Preface. Sci. Total Environ. 408, 2852-2853.

Duan, X., Li, Y., Li, X., et al., 2013. Polychlorinated biphenyls in sediments of the Yellow Sea: distribution, source identification and flux estimation. Mar. Pollut. Bull. 76 (1-2), 283-290.

Fink, U., Hajduk, F., Wei, Y., Mori, H., 2008. Flame Retardants, SCUP Report. SRI Consulting.

Hu, L., Shi, X., Guo, Z., Wang, H., Yang, Z., 2013. Sources, dispersal and preservation of sedimentary organic matter in the Yellow Sea: the importance of depositional hydrodynamic forcing. Mar. Geol. 335, 52-63.

Hu, L.M., Lin, T., Shi, X.F., Yang, Z.S., Wang, H.J., Zhang, G., Guo, Z.G., 2011. The role of shelf mud depositional process and large river inputs on the fate of organochlorine pesticides in sediments of the Yellow and East China seas. Geophys. Res. Lett. 38.

La Guardia, M.J., Hale, R.C., Harvey, E., 2006. Detailed polybrominated diphenyl ether (PBDE) congener composition of the widely used penta-, octa-, and decaPBDE technical flame-retardant mixtures. Environ. Sci. Technol. 40, 6247-6254.

Li, Y., Lin, T., Chen, Y., Hu, L., Guo, Z., Zhang, G., 2012. Polybrominated diphenyl ethers (PBDEs) in sediments of the coastal East China Sea: occurrence, distribution and mass inventory. Environ. Pollut. 171, 155-161.

Lim, D.I., Choi, J.Y., Jung, H.S., Rho, K.C., Ahn, K.S., 2007. Recent sediment accumulation and origin of shelf mud deposits in the Yellow and East China Seas. Prog. Oceanogr. 73, 145-159.

Lin, Y., Qiu, X., Zhao, Y., Ma, J., Yang, Q., Zhu, T., 2013. Polybromobenzene pollutants in the atmosphere of North China: levels, distribution, and sources. Environ. Sci. Technol. 47, 12761-12767.

Milliman, J.D., Meade, R.H., 1983. World-wide delivery of river sediment to the oceans. J. Geol. 91, 1-21.

Melymuk, L., Robson, M., Helm, P.A., Diamond, M.L., 2012. PCBs, PBDEs, and PAHs in Toronto air: spatial and seasonal trends and implications for contaminant transport. Sci. Total Environ. 429, 272-280.

Mitchell, M.M., Woods, R., Chi, L.-H., Schmidt, R.J., Pessah, I.N., Kostyniak, P.J., LaSalle, J.M., 2012. Levels of select PCB and PBDE congeners in human postmortem brain reveal possible environmental involvement in 15q11-q13 duplication autism spectrum disorder. Environ. Mol. Mutagen. 53, 589-598.

Moeller, A., Xie, Z., Sturm, R., Ebinghaus, R., 2011. Polybrominated diphenyl ethers (PBDEs) and alternative brominated flame retardants in air and seawater of the
European Arctic. Environ. Pollut. 159, 1577-1583.

Pan, X., Tang, J., Li, J., Guo, Z., Zhang, G., 2010. Levels and distributions of PBDEs and PCBs in sediments of the Bohai Sea, North China. J. Environ. Monit. 12, 1234-1241.

Pan, X., Tang, J., Li, J., Zhong, G., Chen, Y., Zhang, G., 2011. Polybrominated diphenyl ethers (PBDEs) in the riverine and marine sediments of the Laizhou Bay area, North China. J. Environ. Monit. 13, 886-893.

Qiao, S.Q., Shi, X.F., Wang, G.Q., Zhou, L., Hu, B.Q., Hu, L.M., Yang, G., Liu, Y.G. Yao, Z.Q., Liu, S.F., 2017. Sediment accumulation and budget in the Bohai Sea, Yellow Sea and East China sea. Mar. Geol. 390, 270-281.

Ren, J.L., Zhang, J., Li, J.B., Yu, X.Y., Liu, S.M., Zhang, E.R., 2006. Dissolved aluminum in the Yellow Sea and East China sea - Al as a tracer of Changjiang (Yangtze River) discharge and kuroshio incursion. Estuar. Coast Shelf Sci. 68, 165-174.

Shi, X.F., Chen, C.F., Liu, Y.G., Ren, H., Wang, H.Y., 2002. Trend analysis of sediment grain size and sedimentary process in the central South Yellow Sea. Chin. Sci. Bull. 47, 1202-1207.

SOA, 2014. China Marine Statistical Yearbook 2013. China Ocean Press, Beijing.

Sverko, E., Tomy, G.T., Reiner, E.J., Li, Y.-F., McCarry, B.E., Arnot, J.A., Law, R.J. Hites, R.A., 2011. Dechlorane plus and related compounds in the environment: a review. Environ. Sci. Technol. 45, 5088-5098.

Wang, D.-G., Yang, M., Qi, H., Sverko, E., Ma, W.-L., Li, Y.-F., Alaee, M., Reiner, E.J. Shen, L., 2010. An asia-specific source of dechlorane plus: concentration, isomer profiles, and other related compounds. Environ. Sci. Technol. 44, 6608-6613.

Wang, H., Saito, Y., Zhang, Y., Bi, N., Sun, X., Yang, Z., 2011. Recent changes of sediment flux to the western Pacific Ocean from major rivers in East and Southeast Asia. Earth Sci. Rev. 108, 80-100.

Wang, G., Feng, L., Qi, J., Li, X., 2017. Influence of human activities and organic matters on occurrence of polybrominated diphenyl ethers in marine sediment core: a case study in the Southern Yellow Sea, China. Chemosphere 189 $104-114$

Wang, G., Peng, J., Xu, X., Zhang, D., Li, X., 2016. Polybrominated diphenyl ethers in sediments from the Southern Yellow Sea: concentration, composition profile, source identification and mass inventory. Chemosphere 144, 2097-2105.

Wu, Q, Liu, X., Liang C, Leung JY, S, Li, H., Chen, S, Mai, B, Miao, S, Chen, Y., Wu, Z Chen, Z., 2017. Historical trends and ecological risks of polybrominated diphenyl ethers (PBDEs) and alternative halogenated flame retardants (AHFRs) in a mangrove in South China. Sci. Total Environ. 599, 181-187.

Xiang, N., Chen, L., Meng, X.-Z., Li, Y.-L., Liu, Z., Wu, B., Dai, L., Dai, X., 2014. Polybrominated diphenyl ethers (PBDEs) and dechlorane plus (DP) in a conventional wastewater treatment plant (WWTP) in Shanghai: seasonal variations and potential sources. Sci. Total Environ. 487, 342-349.

Yang, Z.S., Liu, J.P., 2007. A unique Yellow River-derived distal subaqueous delta in the Yellow Sea. Mar. Geol. 240, 169-176.

Yu, Z., Lu, S., Gao, S., Wang, J., Li, H., Zeng, X., Sheng, G., Fu, J., 2010. Levels and isomer profiles of Dechlorane Plus in the surface soils from e-waste recycling areas and industrial areas in South China. Environ. Pollut. 158, 2920-2925.

Zhang, K., Gao, H., 2007. The characteristics of Asian-dust storms during 20002002: from the source to the sea. Atmos. Environ. 41, 9136-9145.

Zhao, G., Wang, Z., Dong, M.H., Rao, K., Luo, J., Wang, D., Zha, J., Huang, S., Xu, Y., Ma, M., 2008. PBBs, PBDEs, and PCBs levels in hair of residents around e-waste disassembly sites in Zhejiang Province, China, and their potential sources. Sci. Total Environ. 397, 46-57.

Zhao, X., Zheng, B., Qin, Y., Jiao, L., Zhang, L., 2010. Grain size effect on PBDE and PCB concentrations in sediments from the intertidal zone of Bohai Bay, China. Chemosphere 81, 1022-1026.

Zhao, Y., Ma, J., Qiu, X., Lin, Y., Yang, Q., Zhu, T., 2013. Gridded field observations of polybrominated diphenyl ethers and decabronnodiphenyl ethane in the atmosphere of North China. Environ. Sci. Technol. 47, 8123-8129.

Zhao, Z., Zhong, G., Moeller, A., Xie, Z., Sturm, R., Ebinghaus, R., Tang, J., Zhang, G., 2011. Levels and distribution of dechlorane plus in coastal sediments of the Yellow Sea, North China. Chemosphere 83, 984-990.

Zhen, X., Tang, J., Liu, L., Wang, X., Li, Y., Xie, Z., 2018. From headwaters to estuary: distribution and fate of halogenated flame retardants (HFRs) in a river basin near the largest HFR manufacturing base in China. Sci. Total Environ. 621, 1370-1377.

Zhen, X., Tang, J., Xie, Z., Wang, R., Huang, G., Zheng, Q., Zhang, K., Sun, Y., Tian, C., Pan, X., Li, J., Zhang, G., 2016. Polybrominated diphenyl ethers (PBDEs) and alternative brominated flame retardants (aBFRs) in sediments from four bays of the Yellow Sea, North China. Environ. Pollut. 213, 386-394.

Zheng, B., Zhao, X., Liu, L., Li, Z., Lei, K., Zhang, L., Qin, Y., Gan, Z., Gao, S., Jiao, L., 2011. Effects of hydrodynamics on the distribution of trace persistent organic pollutants and macrobenthic communities in Bohai Bay. Chemosphere 84, 336-341.

Zheng, Q., Nizzetto, L., Li, J., Mulder, M.D., Sanka, O., Lammel, G., Bing, H., Liu, X. Jiang, Y., Luo, C., Zhang, G., 2015. Spatial distribution of old and emerging flame retardants in Chinese forest soils: sources, trends and processes. Environ. Sci. Technol. 49, 2904-2911.

Zhu, B., Lam, J.C.W., Yang, S., Lam, P.K.S., 2013. Conventional and emerging halogenated flame retardants (HFRs) in sediment of Yangtze River Delta (YRD) region, East China. Chemosphere 93, 555-560. 